\title{
Low Cost Bipolar Plates for Large Scale PEM Electrolyzers
}

\author{
A. S. Gago, A. S. Ansar, P. Gazdzicki, N. Wagner, J. Arnold, \\ K. A. Friedrich
}

Electrochemical Energy Technology Institute of Engineering Thermodynamics German Aerospace Center (DLR)

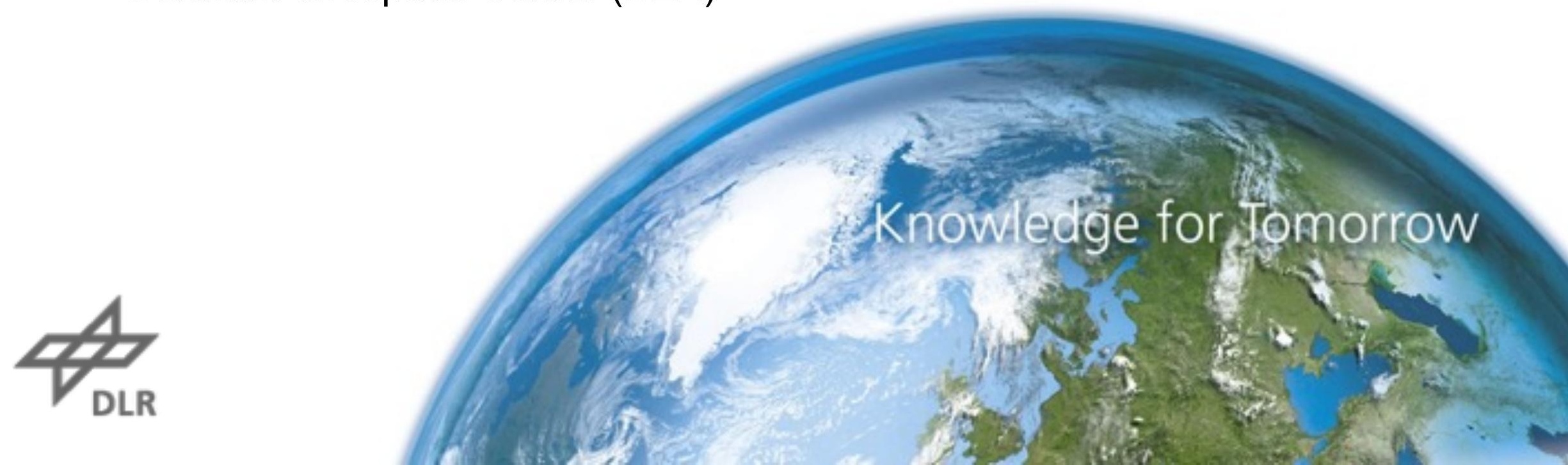




\section{Outline}

- Introduction: $\mathrm{H}_{2}$ as energy vector

- Cost issue in PEM-electrolysis systems

- Strategy for producing the coatings for low cost bipolar plates

- Physical and electrochemical characterization of Au/Ti and Pt/Ti coatings

- Conclusions 


\section{Hydrogen as energy vector}

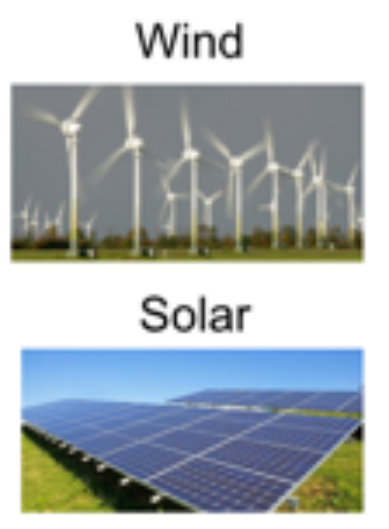

Erneuerbare Energien Gesetz - EEG $40 \%-45 \%$ by 2025 $55 \%-60 \%$ by 2035 $80 \%$ by 2050

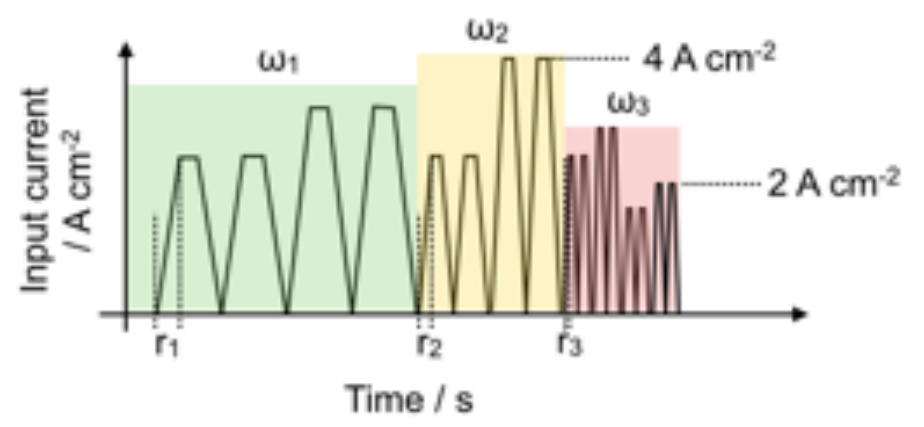

AST protocol based on wind profile

Alkaline electrolysis
Mobility

Reconversion of power

Gas grid

Methane Power-to-Gas

Liquid fuels Power-to-Fuels
Storage medium

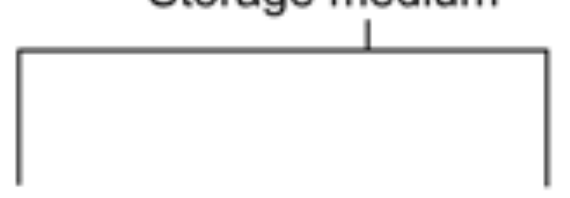

PEM electrolysis

- Uses only DI water

- No additional compressor is needed

- Current density $>6 \mathrm{~A} \mathrm{~cm}^{-2}$

- Rapid response (dynamic operation)

- Expensive

Alcaline electrolyzer $=1,394 \mathrm{USD} / \mathrm{kW}$ PEM electrolyzer $=2,648 \mathrm{USD} / \mathrm{kW}$

"Study on development of water electrolysis in the EU" Fuel Cells and Hydrogen Joint Undertaking 


\section{Cost of a PEM electrolysis stack}

K.E. Ayers et al., ECS Trans. 33 (2010) 3-15. Balance of cell

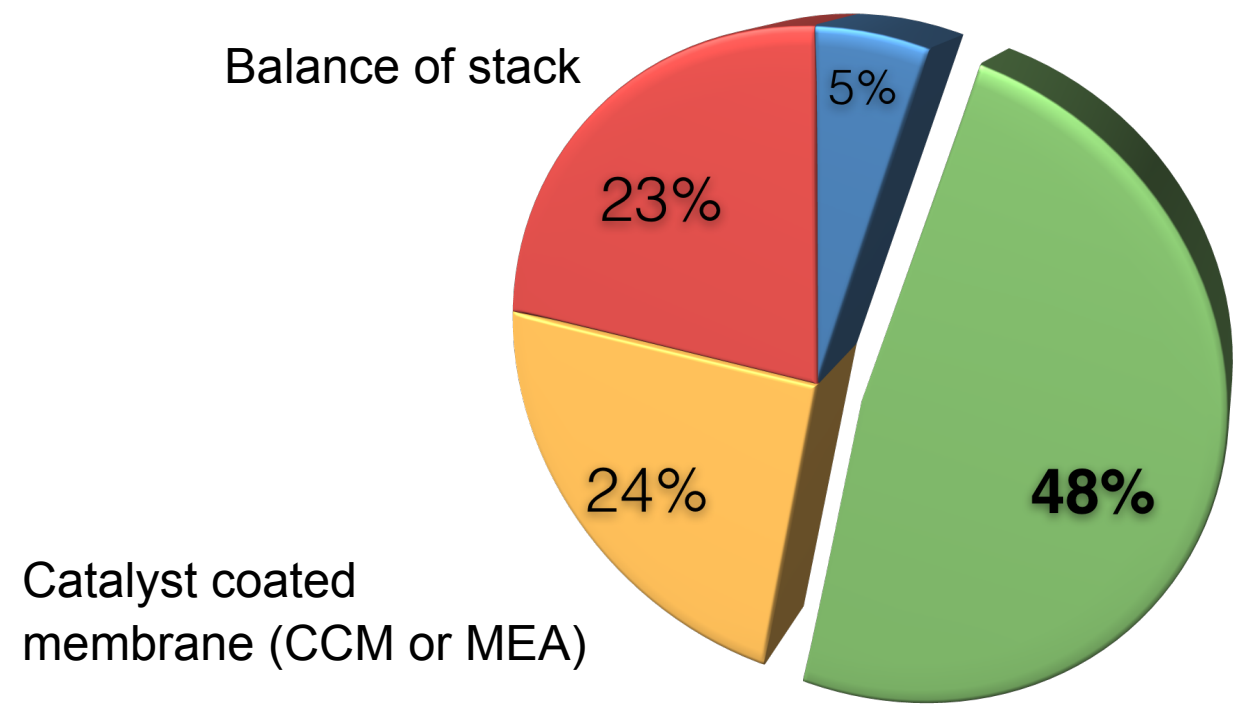

Stainless steel in the PEM electrolysis stack?

Bipolar plates (BPP) and current collectors made of Titanium

\section{CAPEX vs. OPEX}
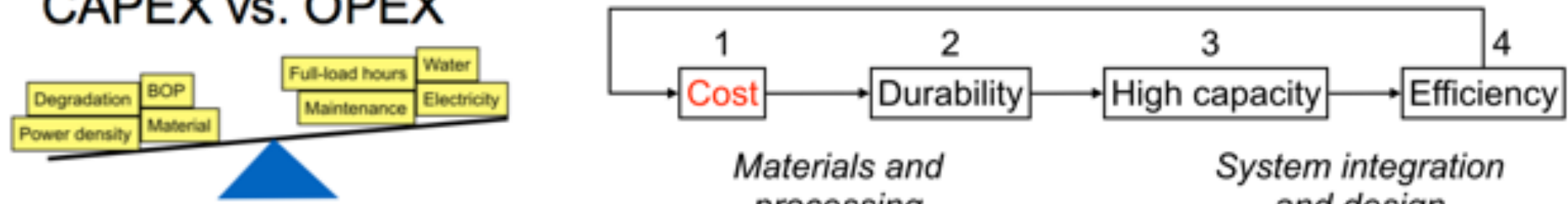

Materials and processing

System integration and design 


\section{Requirements of the protective coating}

1. Resistant to corrosion

2. Low electrical resistivity / High electrical conductivity

3. Strong adherence to the substrate

4. Low cost material, facile and scalable deposition technique

5. Withstand mechanical loads during operation

6. Minimal differences in the coefficient of thermal expansion

7. Resistant to $\mathrm{H}_{2}$ embrittlement (cathode side)

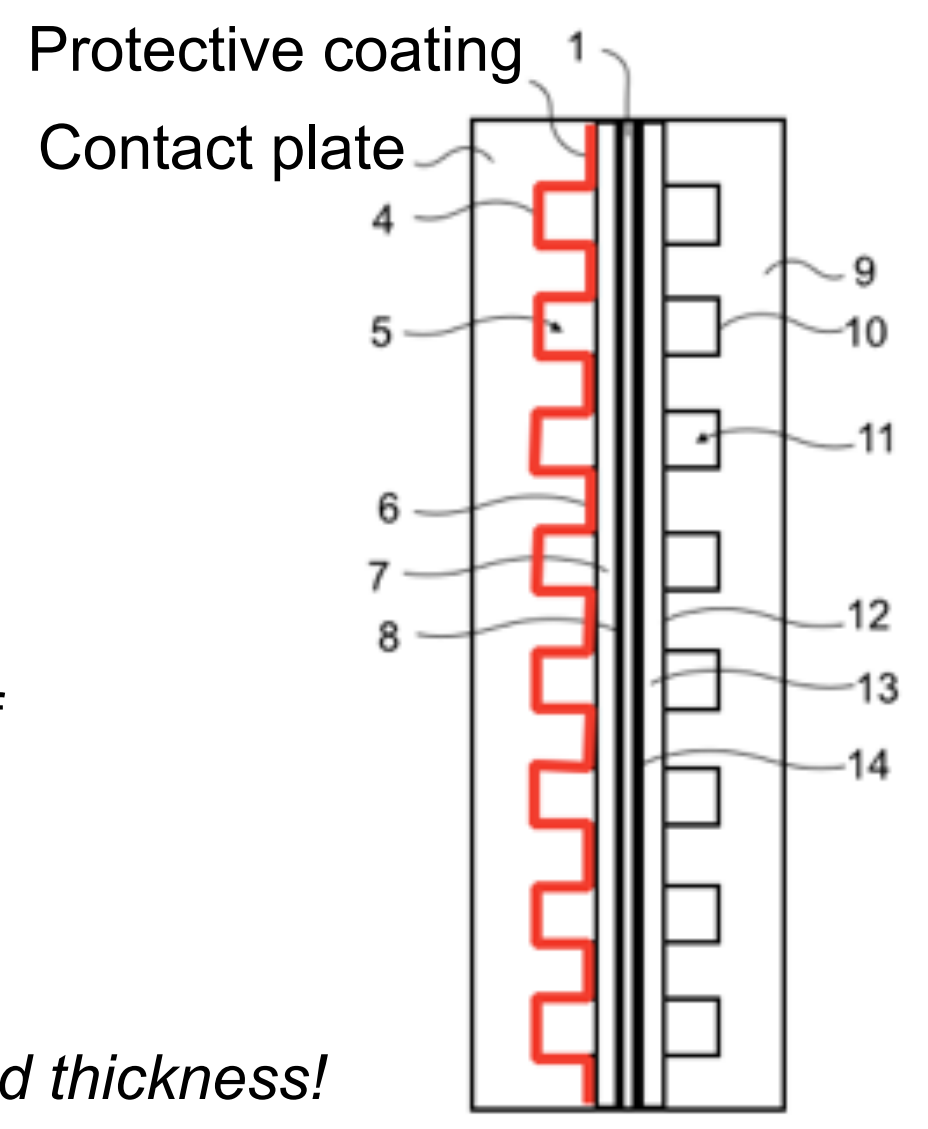




\section{Strategy for coating stainless steel}

Pitting corrosion in PVD coatings

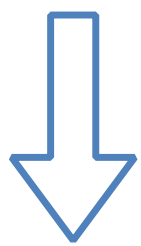

The released $\mathrm{Fe}^{2+}$ poison the CCM of the electrolyzer

S. Sun et al., J. Power Sources 267 (2014) 515.

Coatings for PEM electrolyzers:

Our approach:

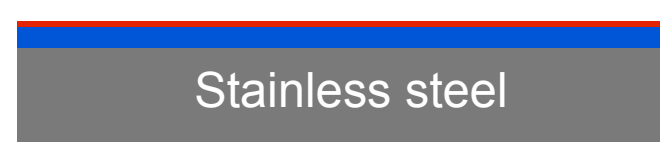

$\mathrm{I}<50 \mu \mathrm{m}$

Coating 1: Titanium coating by vacuum plasma spraying (VPS)

Coating 2: Surface modification of the Ti coating by

electrodeposition or PVD magnetron sputtering

\section{Cost reduction?}

PEMFC: PVD coatings alone meet the DOE requirements.

PEM electrolyzers: current Ti bipolar plates have to be coated to reduce the passivation. 


\section{Physical characterization of Au/Ti coating}

Optical and SEM images
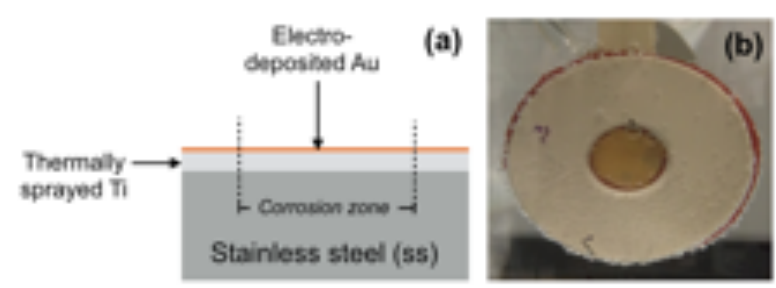

Thermally sprayed Ti coatings with a plasma enthalpy of $21.3 \mathrm{MJ} \mathrm{kg}^{-1}$ electroplated with Au afterwards

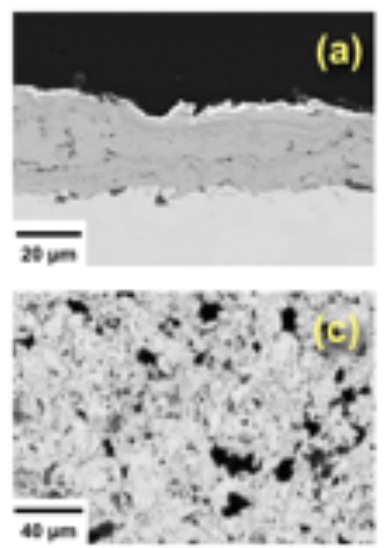

\section{Before}

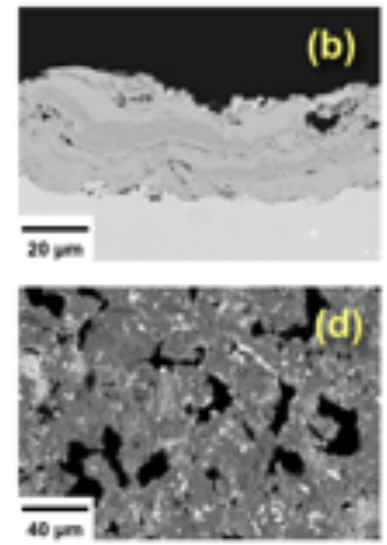

After

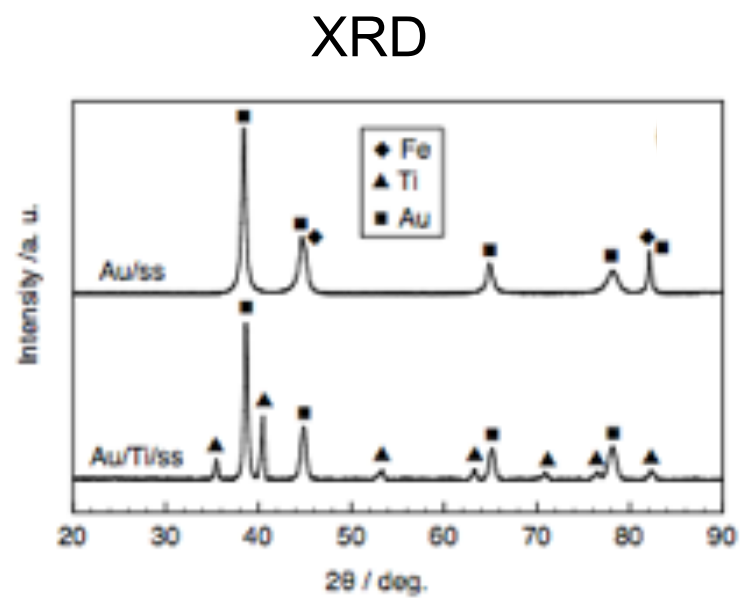

\section{XPS}

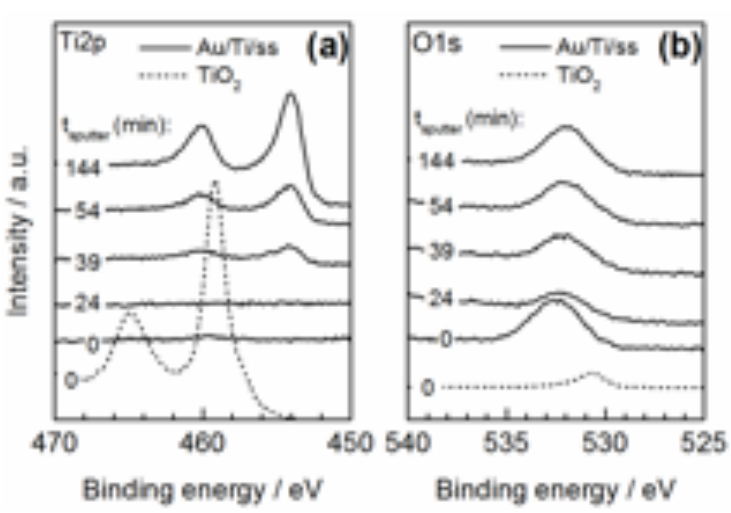

ICR

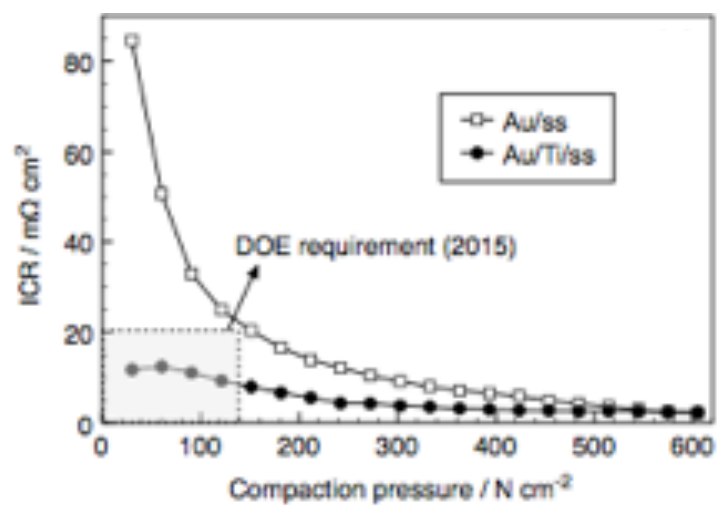

\section{Au/Ti coating}

- Deposited by successive steps of VPS and electrodeposition

- It has a roughness factor of 0.62 . This property allows the adherence of Au on Ti.

- The presence of $\mathrm{TiO}_{2}$ between $\mathrm{Ti}$ and $\mathrm{Au}$ is below the detection limit.

- Meets the DOE requirements of IRC. 


\section{Electrochemical characterization of Au/Ti coating}

Corrosion tests (half-cell)
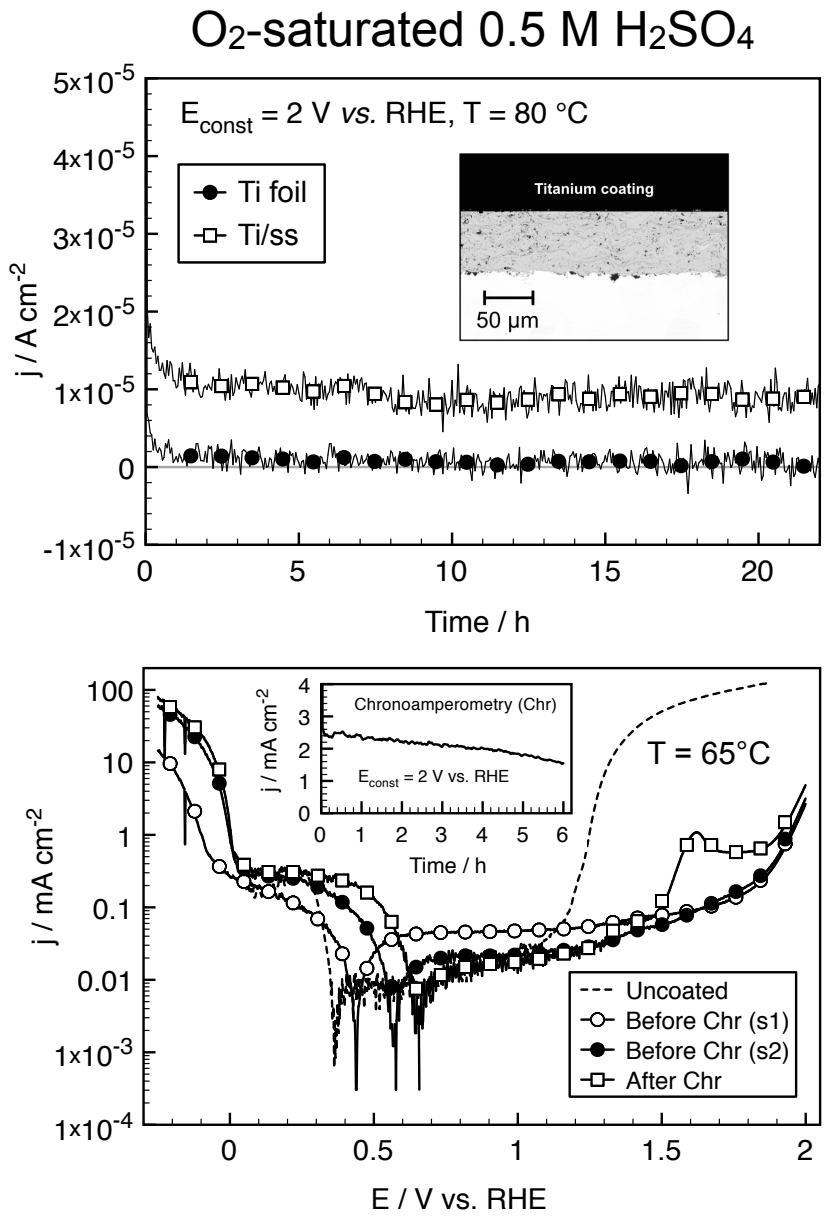

Electrochemical parameters $\quad R_{p}=\frac{\beta_{s} \beta_{c}}{2.3 j_{\mathrm{our}}\left(\beta_{\mathrm{s}}+\beta_{\mathrm{c}}\right)}$

Corrosion potential $\left(E_{\text {corr }}\right)$; corrosion current ( $\left.i_{c o r r}\right)$; anode $\left(\beta_{a}\right)$ and cathode $\left(\beta_{c}\right)$ Tafel slopes and polarization resistance $\left(R_{p}\right)$ of the coated stainless steel before (scan 1 and 2) and after the chronoamperometric (chr) test.

\begin{tabular}{|c|c|c|c|c|c|c|}
\hline Au/Ti/ss & $\begin{array}{c}\mathbf{E}_{\text {corr }} / \mathbf{V} \text { vs. } \\
\text { RHE }\end{array}$ & $\begin{array}{c}\mathbf{j}_{\text {corr }} / \boldsymbol{\mu A} \\
\mathbf{c m}^{-2}\end{array}$ & $\begin{array}{c}\boldsymbol{\beta}_{\mathbf{a}} / \mathbf{m V} \\
\mathbf{d e c}^{-1}\end{array}$ & $\begin{array}{c}\boldsymbol{\beta}_{\mathrm{c}} / \mathbf{m V} \\
\mathbf{d e c}^{-1}\end{array}$ & $\begin{array}{c}\mathbf{R}_{\mathbf{p}} / \mathbf{x} \mathbf{1 0}^{3} \\
\mathbf{\Omega}\end{array}$ & $\begin{array}{c}{\left[\mathrm{Fe}^{2+}\right] /} \\
\mathbf{p p m}\end{array}$ \\
\hline Before chr (s1) & 0,44 & 4,76 & 63 & 91 & 3,40 & - \\
\hline Before chr (s2) & 0,57 & 1,52 & 36 & 35 & 5,08 & - \\
\hline After chr & 0,66 & 3,82 & 148 & 61 & 4,92 & $\mathbf{0}$ \\
\hline
\end{tabular}

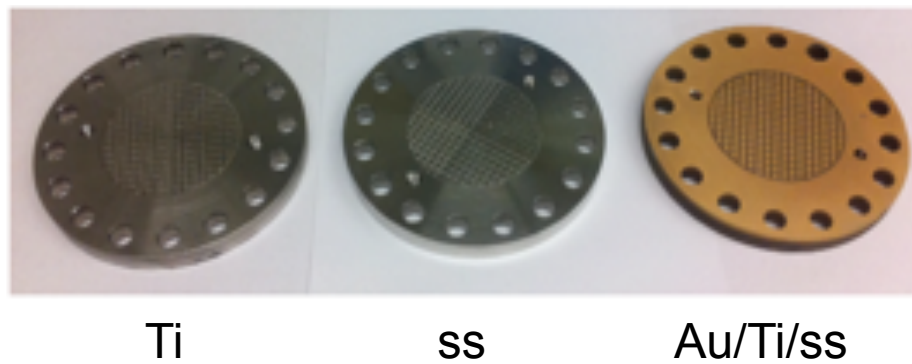

\section{Au/Ti coating}

- The $\mathrm{i}_{\text {corr }}$ of the coated sample is 270 times lower that than the uncoated one.

- It improves the contact between GDL / CC and the BPP.

- The Au modification detached after $6 \mathrm{~h}$ of being constantly polarized at $2 \mathrm{~V}$ vs. RHE. 


\section{Physical characterization of Pt/Ti coating (<4 wt\% PMG)}

Optical and SEM images after corrosion measurements

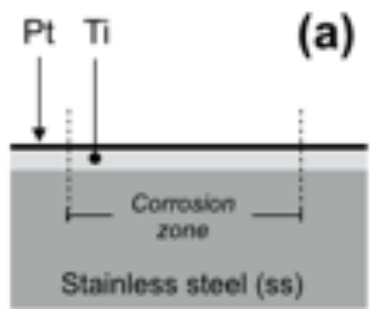

(c)

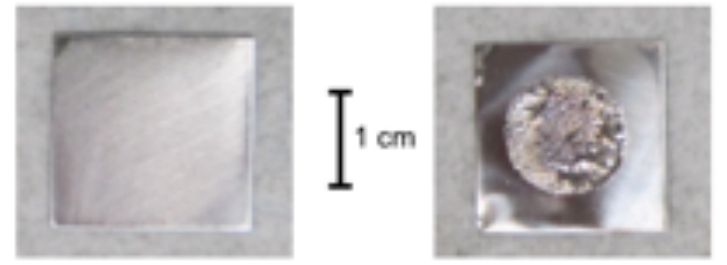

(d)

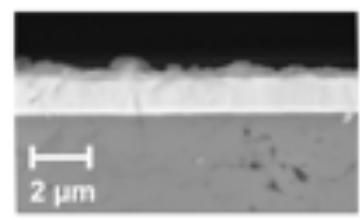

$\mathrm{Pt} / \mathrm{Ti} / \mathrm{ss}$

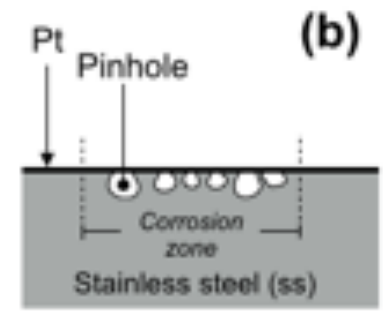

(d)

(e)

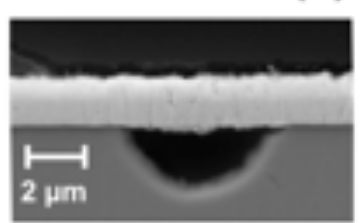

$\mathrm{Pt} / \mathrm{ss}$
XRD

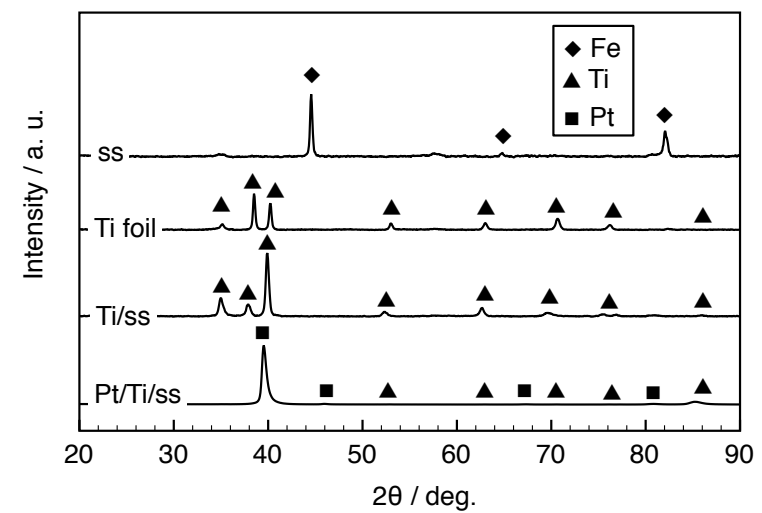

XPS

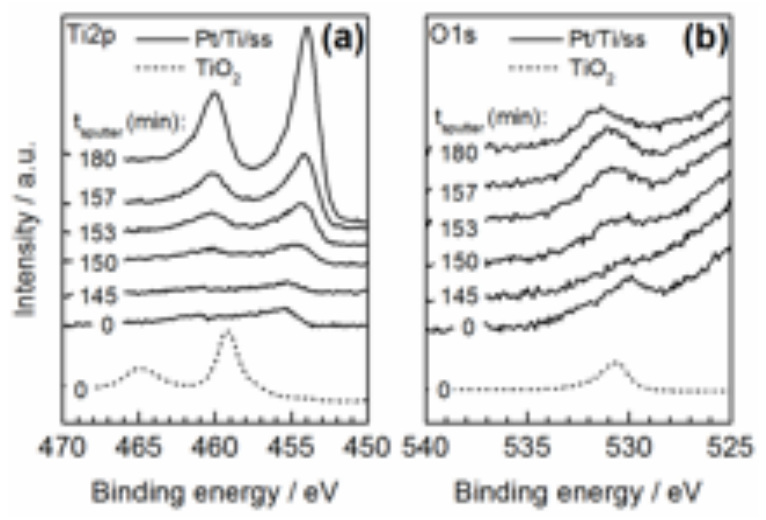

ICR

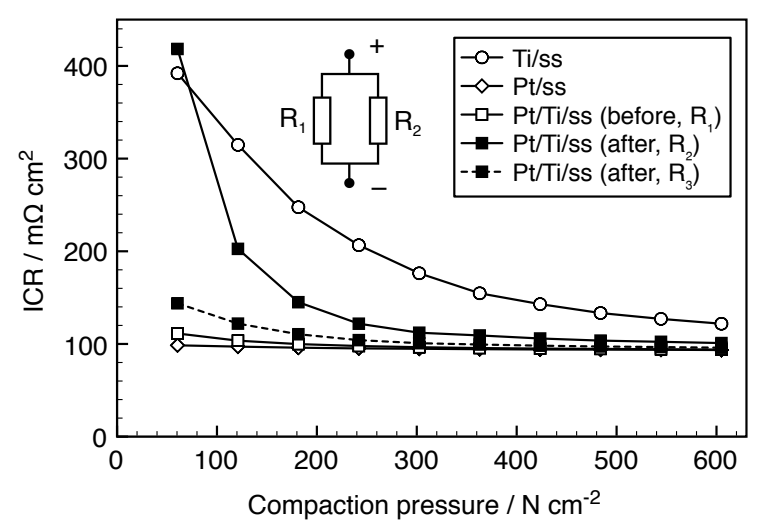

\section{$\mathrm{Pt} / \mathrm{Ti}$ coating}

- Deposited by successive steps of VPS and PVD magnetron sputtering techniques.

- The presence of $\mathrm{TiO}_{2}$ between Ti and Pt could not be detected

- The IRC @ $240 \mathrm{~N} \mathrm{~cm}^{-2}$ of Pt/Ti coating increased 6\% after corrosion measurements. 


\section{Electrochemical characterization of Pt/Ti coating}

Corrosion tests (half-cell)

$\mathrm{O}_{2}$-saturated $0.5 \mathrm{M} \mathrm{H}_{2} \mathrm{SO}_{4}, \mathrm{~T}=65^{\circ} \mathrm{C}$
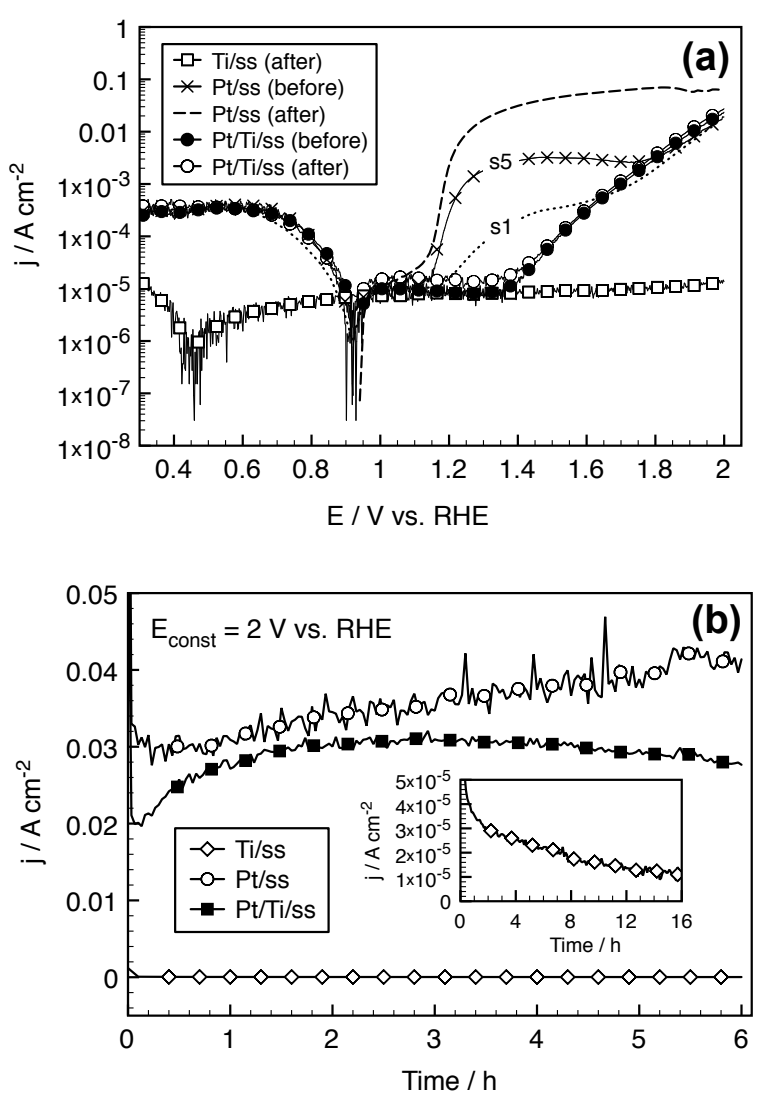

Electrochemical parameters

\begin{tabular}{|c|c|c|c|c|c|c|c|c|c|c|c|}
\hline \multirow[b]{2}{*}{ Sample } & \multicolumn{2}{|c|}{$\begin{array}{l}\mathrm{E}_{\text {corr }} / \mathrm{V} \text { vs. } \\
\text { RHE }\end{array}$} & \multicolumn{2}{|c|}{$\mathbf{i}_{\text {corr }} / \mu \mathrm{A} \mathrm{cm}-2$} & \multicolumn{2}{|c|}{$\beta_{\mathrm{a}} / \mathrm{mV} \mathrm{dec}^{-1}$} & \multicolumn{2}{|c|}{$\beta_{\mathrm{c}} / \mathrm{mV} \mathrm{dec}^{-1}$} & \multicolumn{2}{|c|}{$R_{p} / \times 10^{3} \Omega$} & \multirow{2}{*}{$\begin{array}{l}{\left[\mathrm{Fe}^{2+}\right] /} \\
\text { ppm }\end{array}$} \\
\hline & Before & After & Before & After & Before & After & Before & After & Before & After & \\
\hline $\begin{array}{l}\text { Stainless } \\
\text { steel (ss) }\end{array}$ & 0.36 & 0.54 & 1,7 & 0,6 & 50 & 56 & 20 & 34 & 3,7 & 15,3 & 100.8 \\
\hline Ti/ss & 0.22 & 0.46 & 0,71 & 0,44 & 99 & 102 & 92 & 73 & 29,2 & 42,0 & 0 \\
\hline $\mathrm{Pt} / \mathrm{ss}$ & 0.91 & 0.94 & 1,22 & 0,66 & 53 & 17 & 19 & 21 & 5,0 & 6,2 & 27.73 \\
\hline $\mathrm{Pt} / \mathrm{Ti} / \mathrm{ss}$ & 0.93 & 0.92 & 0,73 & 0,56 & 29 & 13 & 22 & 15 & 7,5 & 5,4 & 0 \\
\hline
\end{tabular}

\section{Contact plates}

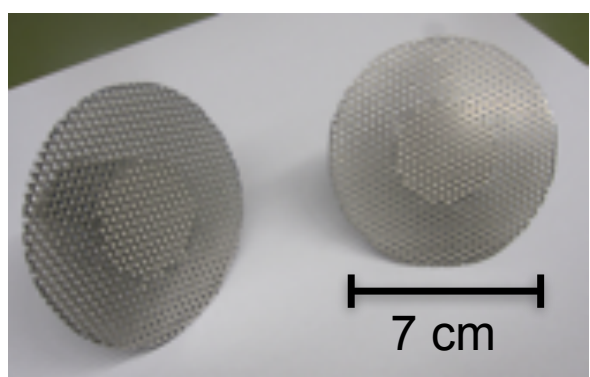

Long term tests in real conditions are currently being carried out by the industry

\section{Pt/Ti coating}

- It successfully protected the stainless steel substrate from corrosion and remained highly conductive at the end of the electrochemical experiments.

- In contrast the Pt coating on ss failed dramatically and the $\mathrm{Fe}^{2+}$ and $\mathrm{Cr}^{3+}$ heavily polluted the electrolyte as result of corrosion of the substrate. 


\section{Cost of the thermally sprayed Ti coating}

Cost of coating BPPs for 1 MW PEM electrolyzer:

$\left(2 \vee @ 2 \mathrm{~A} \mathrm{~cm}^{-2}\right)$

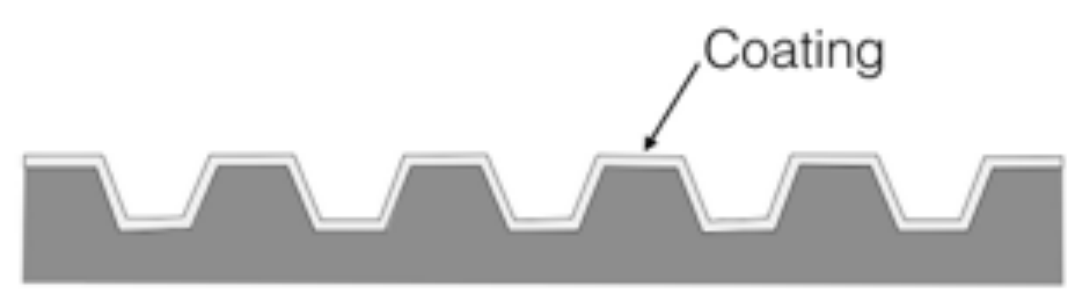

\section{Substrate}

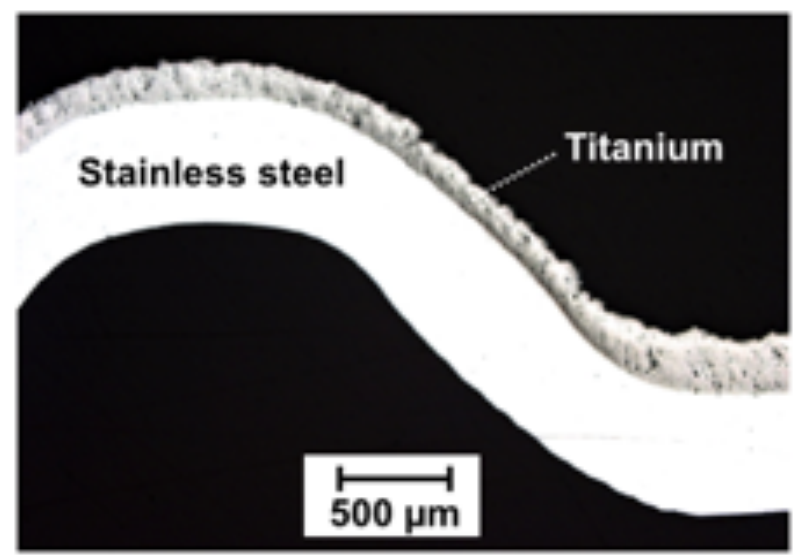

Cost of possible stack base materials and

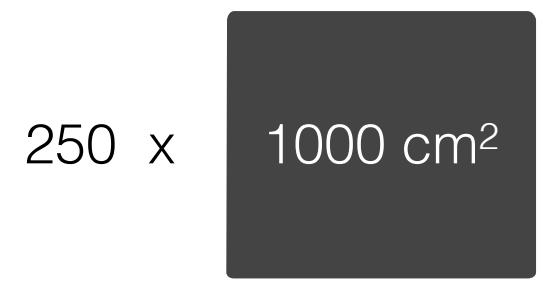

$=2.9$ USD / bipolar plate (considering only consumables, feedstock powder and working hours) their respective electrical conductivities

\begin{tabular}{|c|c|c|}
\hline Metal & $\begin{array}{l}\text { Cost }(30 \times 30 \times \\
0,3 \mathrm{~cm} 3) / \text { USD }^{1}\end{array}$ & $\begin{array}{l}\text { Electrical } \\
\text { conductivity }(\mathrm{S} / \mathrm{m}) \text { at } \\
20^{\circ} \mathrm{C}\end{array}$ \\
\hline Titanium (99.6+) & 614 & $2.38 \times 10^{6}$ \\
\hline $\mathrm{Fe} / \mathrm{Cr} 18 / \mathrm{Ni10}$ (ss 304) & 268 & $1.45 \times 10^{6}$ \\
\hline Copper (99.9\%) & 242 & $5.96 \times 10^{7}$ \\
\hline Aluminium (99\%) & 161 & $3.5 \times 10^{7}$ \\
\hline
\end{tabular}

${ }^{1}$ http://www.goodfellow.com/catalogue/GFCatalogue.php?Language=E 


\section{Conclusions}

- There is an urgent need to reduce the cost of PEM electrolysers for large scale storage of surplus electricity. The bipolar plates are very expensive.

- Dense Ti coatings were produced by vacuum plasma spraying (with high enthalpy) on stainless steel substrates.

- The coatings were evaluated in simulated conditions: $\mathrm{O}_{2}$-saturated $0.5 \mathrm{M}$ $\mathrm{H}_{2} \mathrm{SO}_{4}, 65-80^{\circ} \mathrm{C}, \mathrm{E}_{\text {const }}=2 \mathrm{~V}$.

- Further surface modification resulted in low ICR and full protection of the substrate over extended periods of time.

- The cost of coating stainless steel bipolar plates of $1000 \mathrm{~cm}^{2}$ with Ti, for the Megawatt range, is estimated in 2.9 USD per piece.

- Cheaper materials as $\mathrm{Cu}$ and Al can be used as substrate. The developed coatings are currently being tested in commercial electrolyzers. 


\section{Acknowledgments}

We thank the German Bundes-ministeriums für Bildung und Forschung (BMBF) for financial support in the project No. 0325440A.

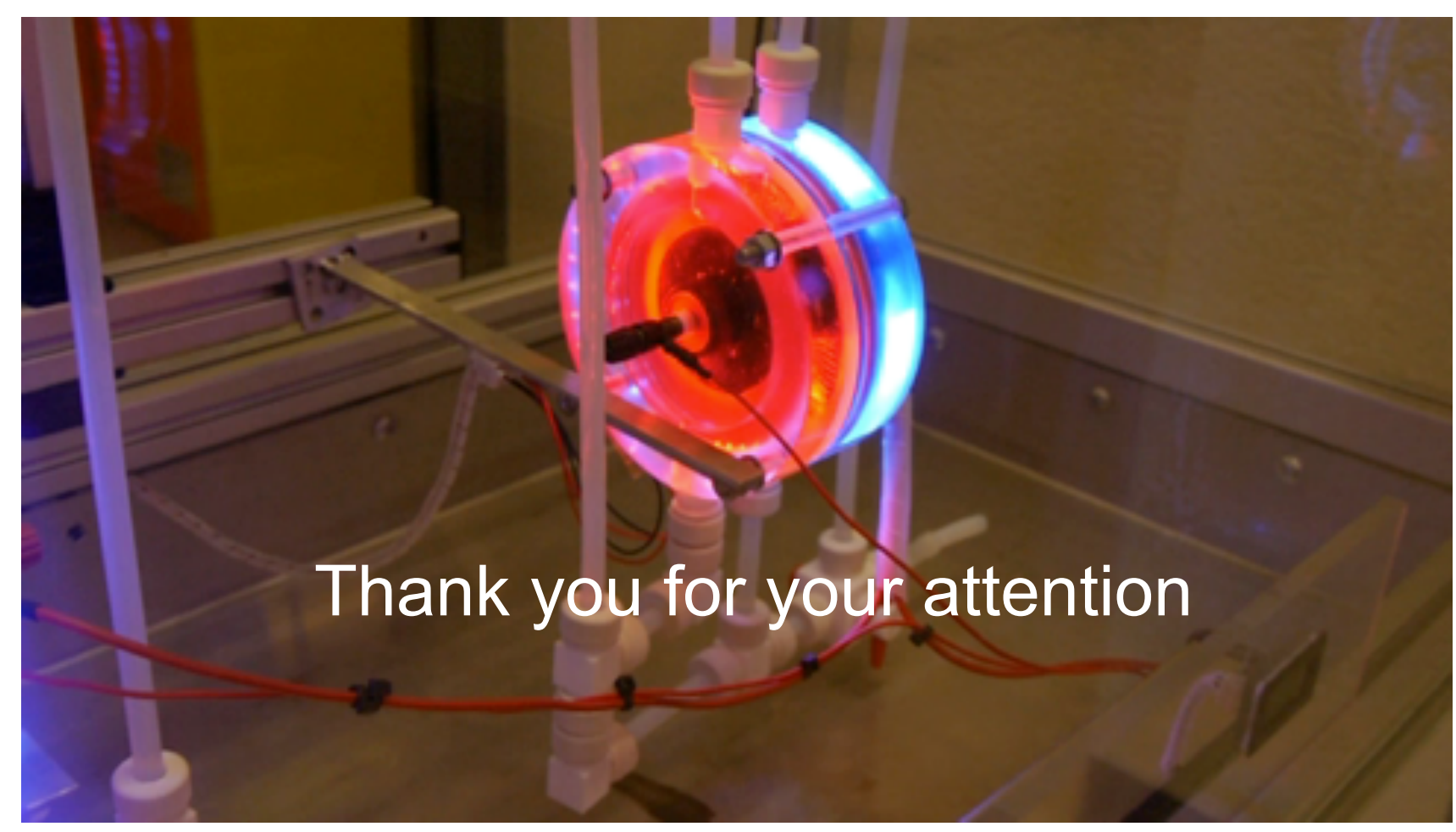

